\title{
The New EFQM Model: What is Really New and Could Be Considered as a Suitable Tool with Respect to Quality 4.0 Concept?
}

\author{
DOI: 10.12776/QIP.V24I1.1415
}

\author{
Jaroslav Nenadál
}

Received: 2020-03-05 Accepted: 2020-03-11 Published: 2020-03-31

\begin{abstract}
Purpose: The paper offers a set of original information based on critical analysis of description two last versions of excellence models presented by the European Organisation for Quality Management (EFQM). The principle goal is to present the main advantages and weaknesses of the latest version of The EFQM Model, especially from a practical point of view with respect to a Quality 4.0 era.
\end{abstract}

Methodology/Approach: Comparative analysis of two relevant documents (EFQM, 2012; EFQM, 2019a) was used as a key method. Discussions with 18 quality professionals from Czech production organisations served as a complementary approach.

Findings: The basic structure of a new model was completely changed. But the description of certain recommendations by way of guidance points are superficial and confusing. It lays stress on the necessity to transform organisations for the future as well as on comprehensive feedback from key stakeholders.

Research Limitation/implication: The latest version of The EFQM Model was published in November 2019, and general knowledge related to this version is naturally limited. Published studies or publicly available experience completely absent. That is why a more in-depth literature review focused on the latest version of The EFQM Model could not be included in this text.

Originality/Value of paper: The paper brings an original set of information that was not published yet before. The value of this set should be examined not only from theoretical but primarily from a practical viewpoint.

Category: Viewpoint

Keywords: excellence; EFQM model; Quality 4.0; feedback; organisation 


\section{INTRODUCTION}

Nowadays, the most of organisations throughout the world must strive to be more and more competitive. In some ways, the TQM philosophy is really recognised as an inspiring idea which supports this effort. So called Business Excellence Models (BEMs) have arose as efficient tools in this field more than 30 years ago (let me remind only the first version of The European Model for TQM established by EFQM in 1991). So called "organisational excellence" concept is very frequently discussed nowadays. American Society for Quality (ASQ, 2015) defines the term "organisational excellence" as ongoing efforts to establish an internal framework of standards and processes intended to engage and motivate employees to deliver products and services that fulfil customer requirements within business expectations". M. Webster (2016) argues that "organisational excellence is delivering, and sustaining the delivery of, outstanding value to all key stakeholders". And according to experts from EFQM: "Excellent organisations are those that achieve and sustain outstanding levels of performance that meet or exceed the expectations of all their stakeholders" (EFQM, 2012). Anyway, excellent organisations have some facets as sustainability, profitability, social responsibility, reputation and good governance. Some other features of the excellent organisations have been already described by Nenadál, Vykydal and Waloszek (2018) for example.

In Europe, The EFQM Excellence Model is the most known and implemented version of BEMs throughout the years. The original version of The European Model for TQM was upgraded by repeatedly way and next-to-last version from 2012 (EFQM, 2012) was fully accepted by management community (not only in Europe!) as the most advanced tool for achieving a long term success and excellent level of an organisational performance. The latest version of this model has been designed from years of experience in changing markets to understand the benefits of organisational analysis, future forecasting and predictive intelligence in driving true transformation. It was launched in November 2019 to replace version from 2012.

\section{RESULTS AND FINDINGS}

Following results and findings were obtained on basis of comparative analysis of two relevant documents (EFQM, 2012; EFQM, 2019a) describing concepts, frameworks and criteria included into last two versions of the model. Presented results and findings will cover four areas of interest that follow.

\subsection{Official Title of the Model}

Version 2012: The EFQM Excellence Model.

Version 2020: The EFQM Model.

Omitting the word "Excellence" at the model's version 2020 can not be evaluated as positive item! After all, from core semantic perspective: any model must be a 
model of something and the new title could be nothing to say and confusing for a lot of managers without relevant quality background!

\subsection{Overall Model Structure}

The EFQM Excellence Model (EFQM, 2012) has comprised three integrated components:

- The Fundamental concepts of Excellence. They were about eight core principles of organisational excellence: adding value for customers, creating a sustainable future, developing organisational capability, harnessing creativity and innovation, leading with vision, inspiration and integrity, managing with agility, succeeding through the talent of people, sustaining outstanding results.

- The Criteria as a framework to help organisations convert fundamental concepts into practice ( 9 main and 32 partial criteria were included into this framework).

- The RADAR logic as dynamic assessment framework that allows to calculate overall organisational excellence level (maturity) through pointing and discovering areas for next improvement of the management system.

On the contrary, The EFQM Model (EFQM, 2019a) does not comprise concepts of excellence explicitly, but they are hidden and integrated into all new sections of the model. The RADAR logic is mostly kept there in original way, also as natural part of the model. Such simplification of overall model's structure wants all managers to perceive as beneficial feature with regard to its practical implementation.

\subsection{Framework of the Criteria}

Let us suppose a framework of criteria, so typical for previous The EFQM Excellence Model is commonly known (see EFQM, 2012; Oakland, 2014; Kanji, 2015) and many others. In comparison, the new model is based on completely changed framework. Now, it consists from three key sections:

- Direction (Why do it?);

- Execution (How do it?);

- Results (What is achieved?).

See Figure 1, the logical linkages among these three sections are evident and they seem to be easy to understand for all, who are engaged in practical development of management systems. 


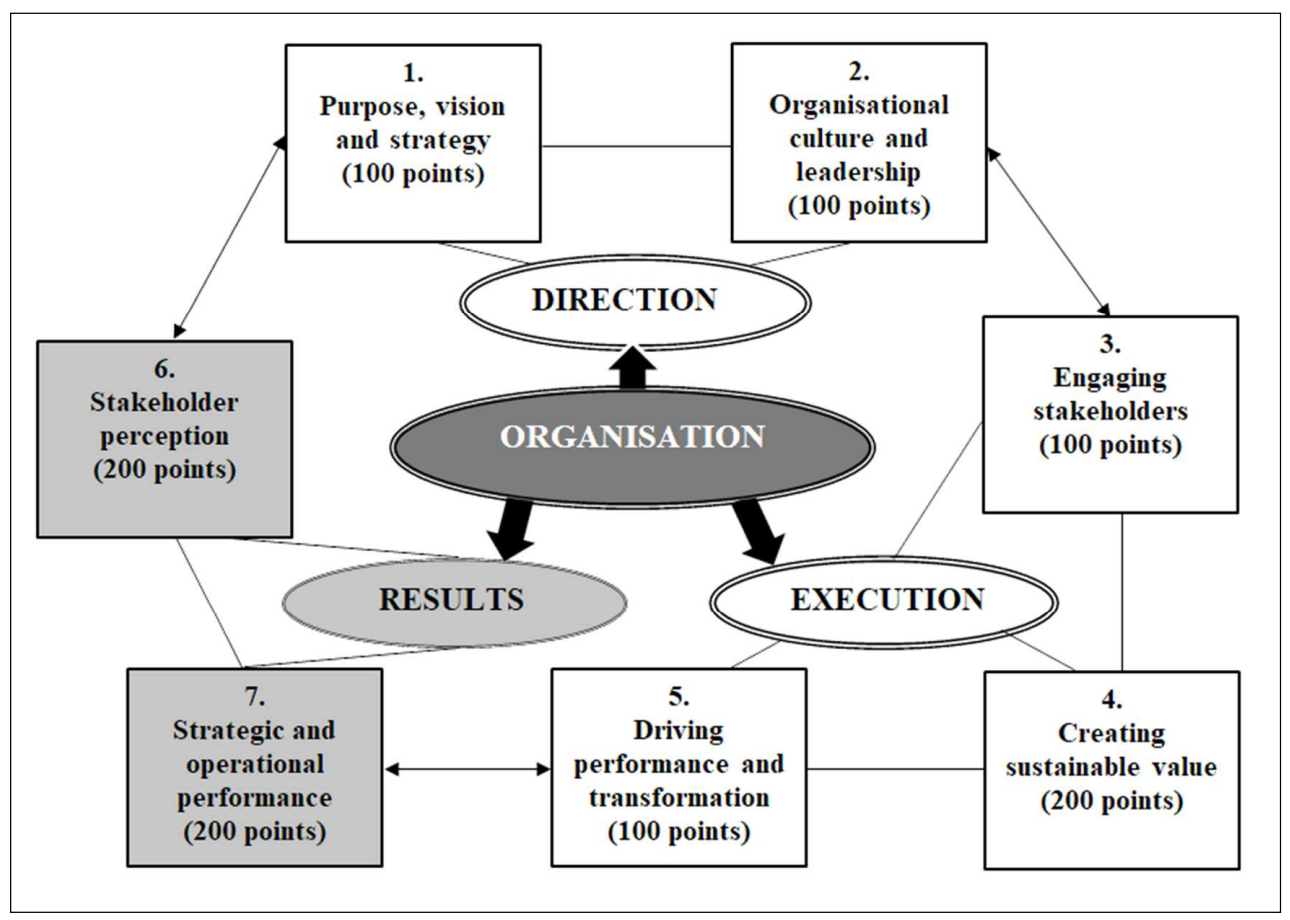

Figure 1 - Structure of the EFQM Model (Adapted According to EFQM, 2019a)

Instead nine main criteria which created framework of previous The EFQM Excellence Model, the new model is inclusive of seven main criteria:

1. Purpose, vision and strategy (5 partial criteria are included in this criterion);

2. Organisational culture and leadership (4 partial criteria are included in this criterion);

3. Engaging stakeholders (5 partial criteria are included in this criterion);

4. Creating sustainable value (4 partial criteria are included in this criterion);

5. Driving performance and transformation (5 partial criteria are included in this criterion);

6. Stakeholder perception (there is no partial criterion);

7. Strategic and operational performance (there is no partial criterion).

Their matching with key sections is visible from Figure 1. Pointing identifies importance of each main criterion. Total amount of poins $(1,000 \mathrm{p}$.) is the same as when scoring organisation's maturity (through self-assessment or external assessing) against The EFQM Excellence Model, version 2012.

In addition, the interactions of the strategic nature of the model (presented by criteria 1 and 2) and operational performance (criteria $3-5$ ) or all organisation's 
results (criteria 6 and 7) represent really remarkable feature that is more evident when compare the previous version of the excellence model. Cause and effect links are much more visible in the new model and it could contribute to the wider acceptance by all levels of managers and academics. Another impressive change bears on the term "sustainable value". It replaces such words as "product" or "service" predominantly. In spite of the "sustainable value" could be less tangible for very practitioners, this term is more generic and underlines necessity to produce and deliver outputs that bring the real value not only for customers but also for another interested parties. And the last logical and positive change: all results regarding to the stakeholders perception (and obtained through effective feedback) are concentrated into one main criterion 6 now. That is remarkably different from the previous The EFQM Excellence Model, where such results were scattered into three different result criteria.

\subsection{Criteria Description through Guidance Points}

From practical viewpoint, a set of so called "guidance points" represents certainly the most important part of each version of EFQM descriptive documents. This set has been developed as a result of the best practice sharing and it was recognised as an inspiring know-how related to each partial criterion of the model. And to tell the truth, the main weaknesses of The EFQM Model, version 2020 are hidden right there! Now, on basis of my personal investigation I would like to call attention only to some of them:

- A quite new term "ecosystem" occurs repeatedly within some guidance points. This term is explained as: "fundamental principle of an ecosystem is interdependence, i.e. something that happens in one part of the system may affect other parts within the system. In the context of the organisation there are many factors external to it that affect how it operates". See chapter Glossary at (EFQM, 2019a). What does it mean? It is obvious the term "ecosystem" is not considered from environmental point of view at all! It is used for external issues of the context of the organisation in sense of ISO 9001 standard (ISO, 2015). And it stands to reason, this could be rather confusing matter in practice!

- A serious recommendation oriented to designing and implementation of a performance management system can be found within criterion 1 of The EFQM Model now. It seems to be nice and rational but some managers could draw the line between an overall management system and the performance management system - what is nonsense of course.

- Comparing the previous version of the model, the latest version underestimates a comprehensive approach to the human resources management. For example, there are no recommendations related to: defining the skills, competencies and people performance level, inspiring people participation of activities that are beneficial for wider society, a teamwork promotion, etc. 
- The guidance points are frequently described only in general, what could be hardly to understand by practitioners. Many wordings are all but tangible. A following formulation included into description of the partial criterion 4.4 (titled as Define and Implement the Overall Experience) should serve as an example: "An outstanding organisation takes advantage and opportunities to personalise the overall experience for its target groups, as well as the specific products, services and solutions" (EFQM, 2019a).

- At The EFQM Model, version 2020 is no recommendation leading to measuring and optimising the impact of organisation's operations, product lifecycle and services on public health, safety and the environment. The organisation's role in area of social responsibility moves downwords in reality.

- An accent on framework of key processes using for efficient organisation's strategy implementation is also missing, as well as underlining the role of a process owners, which can lead to underestimating of a process approach as a basis for any management system development and improvement.

- The necessity of benchmarking activities focused especially on performance indicators is visibly repressed at the guidance points of the latest version of the model, even though benchmarking is still mentioned as one pillar of The RADAR logic.

- Unlike The EFQM Excellence Model (EFQM, 2012), any recommended shortlist of suitable indicators completely absents at The EFQM Model (EFQM, 2019a) within description of new results criteria 6 and 7. We can read only about general areas (as a delivery of overall customer experience, a social and environmental responsibility, an achieving gender balance, a partners experience of dealing with the organisation, a financial performance, an achievements in driving transformation, etc.).

Apart from weaknesses mentioned above, we can discover many other shortcomings mostly tied to difficult understanding of various formulations, missing definitions of terms etc.

But on the contrary, when reviewing a new set of the guidance points, we are able to register also some positive changes in comparison to The EFQM Excellence Model (EFQM, 2012). The list of the most interesting and useful items follows:

(+) Probably, the most important change is associated with a support and providing creativity and innovation. Minimally 8 different guidance points related to the creativity and innovations are newly concentrated into special partial criteria 2.3 and 5.3 as a response on fact that a lot of a European companies have got into the slow lane in this area. 
$(+)$ Other underlined relationships bear on so called business and governing stakeholders as investors, funding organisations, regional bodies, public authorities etc. An outstanding organisations should make sure such relationships are mutually beneficial.

$(+)$ What differentiates the organisation from others, including competitors, this should be recognised and communicated as a natural part of values delivered to various stakeholders, including customers and partners.

$(+)$ Certain recommendations related to the risks identification, analysis, evaluation and treatment go beyond mere financial risks at the latest version of The EFQM Model. Now, the risk management should cover all categories of risks, including legal, societal, cyber security, etc.

(+) An asset management should reflect a Circular economy principles in case a certain infrastructure must be disposed.

\section{THE EFQM MODEL, VERSION 2020 AND THE QUALITY 4.0 CONCEPT}

We are able to notice also another two remarkable changes by way of quite new items among all guidance points in the latest version of The EFQM Model:

(+) Partial criterion 5.2 is strongly oriented to necessity to transform current organisation for the future.

(+) Main criterion 6 (Stakeholders perception) is fully based on a comprehensive feedback from key stakeholders. Their perceptions should be obtained from number of sources, including social media, advocacy, etc.

These recommendations ought to be seen as a nice challenge faced the Quality 4.0 concept, especially in area of $\mathrm{B} 2 \mathrm{~B}$ relations.

Quality 4.0 is an immediate reference to Industry 4.0. Unfortunately, none serious articles can be referred in this area at present. This topic is too fresh and therefore the discussions and information sharing are mostly held through Internet blogs, for example Jacob (2017a), Köpper et al. (2019), Rigert and Writer (2020). The most valuable studies in area of Quality 4.0 are probably performed by LNS Research Company. According its investigations, the most of industrial companies will have to be transformed towards Industry 4.0 during next five years, including quality management conversion (Jacob, 2017b). When study these sources, we can identify following features of the Quality 4.0 concept:

- This term comes from Industry 4.0 and it covers all issues of an advanced quality management at digital era. 
- It is not closed-ended term. It should be seen as a certain umbrella term, that openly describes a new-data driven approach to manage of all quality requirements.

- Four main areas to address by Quality 4.0 are frequently stressed: design and development, production, service and company culture. Especially, the last item must be recognised at our environment - see Zgodavova, Hudec and Palfy (2017) for more details.

- A special attention is paid to the methods and tools enabling agile B2C communication and efficient feedback.

- An extensive IT support is crucial precondition for Quality 4.0 practical establishing.

- A reliable and quick connectivity as well as interaction among machines, people, organisational units and stakeholders are not aim, these connections are looked upon a means for effective and efficient quality improvement and innovations.

- The Quality 4.0 effectively blends new technologies (cloud computing, big data, artificial intelligence, machine learning, Internet of things, etc.) with proved quality management methods and tools.

- The TQM philosophy (including active participation of all staff) is respected as a natural part of Quality 4.0.

- A transformation from traditional quality management to the Quality 4.0 concept will take huge financial resources, people knowledge and time too.

- So called "Closed-Loop Quality Management Systems" are generally considered as suitable basis for sequential implementation of the Quality 4.0 concept, not only within B2B area.

The last item deserves some additional remarks. K. Sundaram (2018) argues the organisations belief that traditional quality management systems are increasingly making a move towards the more future-ready and a closed-loop approach is expressed there. Goulévitch (2018) lists eight examples of how the closed-loop quality management systems should function, including transparency in production processes, traceability, integrating with information systems, facilitating Lean processes, etc.. Lim (2020) underlines that the Quality 4.0 and the closed-loop quality management enable to transform the conventional quality management in real time. Since an exact definition of the closed-loop quality management system is not available till the time, let me see it as a natural part of the overall organisation's management system based on advanced quality management principles that enables to connect all quality management processes and performance data with aim to improve the organisational quality and achieve the organisational excellence. The closed-loop quality management systems 
should be created and developed as a comprehensive mixture of an internal, external, horizontal and vertical loops. These loops must naturally:

- cover all organisational levels, from strategic to shop floor,

- connect the organisation with all key stakeholders, not only with customers,

- be tailored according specific organisational environment and should represent a unique set of processes,

- be based on agile feedback loops in advance.

At present, such quality management systems are in progress, especially at automotive industry. But when we use the Industry 4.0 Maturity Index perspective, distinguishing six stages in the Industry 4.0 development, such as computerisation, connectivity, visibility, transparency, predictive capacity and adaptability - (see Shuh et al., 2017), such effort is mostly at the beginning.

\section{CONCLUSION}

The organisational excellence cannot be considered as overcomplicated matter. On the contrary, it must be seen as a nice opportunity for sustainable business success! Therefore, various excellence models are expected to play a crucial role at this effort. According to our investigations and when consulting the latest version of The EFQM Model, we are able now to declare some final remarks concerning possible implementation of this model with respect for current trends covered by the Quality 4.0 concept:

a) The EFQM Model will stay a very advanced and generic tool for any organisation striving to be successful on the excellence journey.

b) Huge group of creators (nearly 2000 change experts and leaders from 60 diverse organisations (EFQM, 2019b; EFQM, 2019a)) had original aim: to shift the new model from being only assessment tool to one that offers a vital framework and methodology to help with changes and transformation. Under my opinion, this goal was achieved only partially.

c) Basic structure of The EFQM Model was completely changed (see Fig. 1). The arrangement, which covers three key sections and seven main criteria, is undoubtebly a positive and radical shifting - it is more logical and simplier in comparison to The EFQM Excellence model, version 2012. But this advantage is called into question through following shortcomings:

d) Some terms used there are unclear, defined by inproper way only (or not defined at all) what can cause a confusion for a lot of practitioners and make troubles within the model implementation.

e) The description of many guidance points is superficial only, ambiguous and less concrete. 
f) Some important recommendations absent completely within sections Direction or Execution, for example in area of the human resources management, the process approach establishing, etc.

g) Any recommended set of suitable performance indicators is absolutely missing in section Results.

h) A long-term orientation to the Quality 4.0 concept is not mentioned by explicit manner at The EFQM Model, it is slightly hidden, but it is incorporated through stressing a necessity to transform current organisations for the future as well as on a comprehensive feedback from key stakeholders. The closed-loop quality management systems can be seen as efficient contribution to such transformation.

Briefly to say: the latest version of The EFQM Model is not better or worse in comparison to the version from 2012. Simply expressed: it is else one. Advantages and weaknesses are mutually balanced there and only a near future will show if this model is valuable tool for digital transformation of the organisations and their management systems. While the previous versions of excellence models were matter of people engagement, education, training and motivation in advance, a combination of the organisational excellence and the Quality 4.0 concept will require also considerably investments and a quite new work position development. Anyway, a huge challenge occurs in front of us!

\section{ACKNOWLEDGEMENTS}

This work was supported by the European Regional Development Fund under grant "A research Platform Focused on Industry 4.0 and Robotics in the Ostrava Agglomeration", project No. CZ.02.1.01/0.0/0.0/17_049/000845 and VŠBTechnical University of Ostrava under grant No. SP 2020/51 "Development of selected areas of modern quality management systems with respect to Quality 4.0 concept".

\section{REFERENCES}

American Society for Quality (ASQ), 2015. What is Organizational Excellence?. [online] Available at: <https://asq.org/quality-resources/organizationalexcellence $>$ [Accessed 12 February 2020].

EFQM, 2012. EFQM Excellence Model 2013. Brussels: EFQM Representative Office.

EFQM, 2019a. The EFQM Model. Brussels: EFQM.

EFQM, 2019b. How is the EFQM Model 2020 development doing?. [online] Available at: <https://www.efqm.org/index.php/2019/05/10/how-is-the-efqmmodel-2020-development-doing/> [Accessed 12 February 2020]. 
Goulévitch, V., 2018. Eight examples of properly working closed-loop quality system. [online] Available at: <https://www.controleng.com/articles/eightexamples-of-a-properly-working-closed-loop-quality-system/> [Accessed 13 November 2018].

ISO, 2015. ISO 9001 Quality management systems - Requirements. Geneve: ISO. Jacob, D., 2017a. What is Quality 4.0.. [online] Available at: $<$ www.juran.com/blog/quality-4-0-the-future-of-quality $>$ [Accessed 14 January 2019].

Jacob, D., 2017b. Quality 4.0 Impact and Strategy Handbook. Cambrige: LNS Research.

Kanji, K.G., 2015. Measuring Business Excellence. New York: Routledge.

Köpper, D., Knizek, C., Ryeson, D. and Noecker, J., 2019. Quality 4.0 Takes More Than Technology. [online] Available at: $<$ www.bcg.com/publications/2019/quality-4.0-takes-more-thantechnology.aspx $>$ [Accessed 7 January 2020].

Lim, J.S., 2020. Quality Management in Engineering. A Scientific and Systematic Approach. Boca Raton: CRC Press.

Nenadál, J., Vykydal, D. and Waloszek, D., 2018. Organizational Excellence: Approaches, Models and their use in Czech Organizations. Quality Innovation Prosperity, 22(2), pp.47-64. DOI: 10.12776/QIP.V2212.1129.

Oakland, J.S., 2014. Total Quality Management and Operational Excellence. Text with Cases. Fourth Edition. London: Routledge.

Rigert, M., Writer, S., 2020. Why Quality 4.0 Should Be a Top Priority for Quality Managers. [online] Available at: <www.mastercontrol.com/qxplifetime/the-quality-leaders-guide-to-quality-4.0/> [Accessed 19 January 2020].

Shuh, G., Anderl, R., Gausemaier, J., Hompel, M. and Wahlster, W., 2017. Industrie 4.0 Maturity Index. Managing the Digital Transformation of Companies (acatech STUDY). Munich: Herbert Utz Verlag.

Sundaram, K., 2018. Quality in the Future of Manufacturing. Santa Clara CA: Frost \& Sullivan.

Webster, M., 2016. So what is organizational excellence. [online] Available at: $<$ https://realorganisationalexcellence.com/2011/08/25/so-what-is-organisationalexcellence/> [Accessed 12 December 2017].

Zgodavova, K., Hudec, O. and Palfy, P., 2017. Culture of quality: insight into foreign organisations in Slovakia. Total Quality Management \& Business Excellence, 28(9-10), pp.1054-1075. DOI: 10.1080/14783363.2017.1309120. 


\section{ABOUT THE AUTHOR}

Jaroslav Nenadál - VSB-Technical University of Ostrava, Czech Republic, Faculty of Materials Science and Technology, Department of Quality Management, Prof., e-mail: jaroslav.nenadal@vsb.cz, Author's ORCID: 00000003-1526-8694.

\section{CONFLICTS OF INTEREST}

The author declares no conflict of interest. The funders had no role in the design of the study; in the collection, analyses, or interpretation of data; in the writing of the manuscript, or in the decision to publish the results.

(C) 2020 by the authors. Submitted for possible open access publication under the terms and conditions of the Creative Commons Attribution (CC-BY) license (http://creativecommons.org/licenses/by/4.0/). 